\title{
The impacts of type and proportion of five different asphalt modifiers on the low-temperature fracture toughness and fracture energy of modified HMA
}

\author{
Mehdi Fallah Tafti, Seyyed Abuzar Hoseini Aqda \\ Civil Engineering Department, Faculty of Engineering, Yazd University, Yazd, Iran, \\ Fallah.Tfati@Yazd.ac.ir, bttps://orcid.org/0000-0001-6844-3316 \\ seyyedabuzar@gmail.com \\ Hamed Motamedi \\ General Directorate of Roads and Urban Development of Yazd Province, Yazd, Iran \\ Motamedi_iranroad@yahoo.com
}

\begin{abstract}
Low-temperature fracture toughness and fracture energy are two important measures that could be used to investigate the impacts of using asphalt modifiers on the performance of asphalt pavements in cold regions. The aim of this research was to identify the impacts of using various proportions of five different asphalt modifiers on the fracture toughness and the fracture energy of Hot Mix Asphalts (HMA) under mode I loading and at low environmental temperatures. The asphalt modifiers used for this purpose were: Elastoplastomer Polymer Strings (EPS), Parafiber, Sulfur Polymer, Polyolefin-Aramid Compound Structural Fibers (PACSF) and Sasobit. These modifiers were individually used at three different proportions to produce Semi-circular Bend Specimens containing vertical edge crack. Each specimen was then tested under symmetric monotonic three-point bend loading at $15^{\circ} \mathrm{C}$. The results indicated that, except for the EPS, both fracture toughness and fracture energy were increased with an increase in the modifier proportion. The highest increase in both measures was observed in the specimens modified with the PACSF, closely followed by specimens modified with the Parafibers. The least increase in these two measures was observed in the specimens modified with the Sulfur Polymer. The results indicated the applicability of examined modifiers to improve the resistance of HMA to crack initiation and crack growth at low temperatures.
\end{abstract}

KEYWORDS. Mode-I Fracture Toughness; Mode-I Fracture Energy; Hot Mix Asphalt; Low-Temperature Cracking; Asphalt Modifiers.

\section{OPEN ACCESS}

Citation: Fallah Tafti, M., Hoseini Aqda, A., Motamedi, H., The Impacts of Type and Proportion of Five Different Asphalt Modifiers on the Low-Temperature Fracture Toughness and Fracture Energy of Modified HMA, Frattura ed Integrità Strutturale, 47 (2019) 169-185.

Received: 07.10.2018

Accepted: 05.11.2018

Published: 01.01.2019

Copyright: (C) 2019 This is an open access article under the terms of the CC-BY 4.0, which permits unrestricted use, distribution, and reproduction in any medium, provided the original author and source are credited. 


\section{INTRODUCTION}

$\mathrm{T}$

he major deterioration mode of road asphalt pavements at low ambient temperatures is mainly in the form of thermal cracks and brittle fractures. This is mainly due to the solid state and elastic behavior of bitumen and subsequently asphalt mixtures at these conditions. A number of researches have previously conducted to enhance the performance of asphalt mixtures in these conditions. Fracture Mechanics is one of the analytical tools that has been widely used to evaluate the performance of asphalt mixtures at different temperatures and conditions over the last three decades [1-23]. It has also been used in researches concerned with the performance of asphalt mixtures at low temperatures $[1,2,3$, $4,5,6,7]$. These studies have indicated that initiation and propagation of cracks in these situations can be investigated under monotonic pure tension mode (Mode I), provided that the Linear Elastic Fracture Mechanics (LEFM) dominates the testing conditions, i.e. the testing is undertaken at subzero temperatures [2, 3, 4, 8] and under fast loading conditions [2]. At higher temperatures and under slow loading, asphalt mixtures tend to demonstrate a viscoelastic or even viscous behavior. Using Fracture Mechanics approach, based on numerical fracture analysis and/or fracture toughness tests described in section 4, a number of studies have been undertaken to investigate the impacts of involved parameters such as asphalt mixture properties, testing temperature, loading condition, specimen shape, and applied asphalt modifier type [1-23]. A summary of major findings from such researches is described below.

In respect with the mixture properties, Behbahani et al. [9], Aliha et al. [5] and Aliha et al. [8] in their experimental studies concluded that the fracture toughness of asphalt mixtures at low temperatures would be reduced with an increase in their air void and a decrease in their aggregate size. Aliha et al. [8] also realized that with an increase in the bitumen hardness, the mode I fracture toughness of asphalt mixtures would significantly be increased but this behavior is less pronounced when switching to mode II loading. They also concluded that with an increase in the nominal size of aggregates used in the asphalt mixtures, the mixed mode fracture toughness, especially under the dominated mode II loading, would be increased. Their findings also indicated that limestone aggregates have a higher fracture toughness than siliceous aggregates. More recently, Ren and Sun [10] investigated the impact of void characteristics (porosity, void size, and void distribution) on the fracture performance and crack propagation of HMA. A combination of experiments and heterogeneous simulations based on the discrete element method was applied. The fracture tests were performed on a series of edge cracked Semi Semi-Circular Bend (SCB) specimens fracturing under different loading modes at $-6^{\circ} \mathrm{C}$ and $10^{\circ} \mathrm{C}$. The results indicated that the fracture toughness and the time at which peak load occurs reduced as the porosity and void size increased and the impact of void size was more significant than that of porosity. At $-6^{\circ} \mathrm{C}$, the impact of void characteristics on crack propagation was not significant in mode I and mixed mode I/II loading.

In terms of specimen shape, the findings of a study by Ameri et al. [3] indicated that it would be easier to use SCB specimens containing vertical edge crack rather than other specimen geometries when they are used for crack propagation experiments at low temperatures. They modeled two types of SCB specimens under different loading modes using the finite element analysis and produced a wide range of shape factors. Also, Saha and Biligiri [11] in a review of previous studies concluded that the SCB geometry is a suitable shape for specimens used in the crack propagation experiments.

In terms of loading condition, Pirmohammad and Ayatollahi [6] in their experimental study on the fracture resistance of HMA under different loading modes showed that this factor would influence the fracture resistance of HMA significantly. Saha and Biligiri [11] in their research concluded that the monotonic loading can be used to obtain useful information on the fracture behavior of SCB specimens but this type of loading is not appropriate when fatigue behavior of asphalt mixtures is being investigated. Also, Aliha et al [8] in their research showed that the effects of binder and asphalt modifier on the fracture toughness were noticeable when the asphalt mixtures were subjected to pure or dominantly mode I loading condition.

In terms of testing temperature, Pirmohammad and Ayatollahi [6] in their experimental study on the fracture resistance of HMA under different testing temperatures indicated that for all of the fracture tests they performed under different loading modes, the fracture toughness increased with a decrease in temperature but below a certain temperature threshold (i.e. $20^{\circ} \mathrm{C}$ ), it started decreasing. Aliha et al. [5] in a series of experiments performed at four different subzero temperatures ($24^{\circ} \mathrm{C},-18^{\circ} \mathrm{C},-12^{\circ} \mathrm{C}$ and $\left.-6^{\circ} \mathrm{C}\right)$ indicated that the fracture toughness would increase with a decrease in temperature. However, below a certain temperature threshold, which was identified as the lower Performance Grade (PG) limit of each bitumen, the fracture toughness would decrease with further reductions in the temperature. This reduction was attributed to the nucleation of micro cracks inside the bitumen which may lead to more brittleness of the bitumen and also reduction in the bonding between the bitumen and aggregates.

In terms of modifier type, Behbahani et al. [9] investigated the mode I fracture toughness of asphalt mixtures modified with Crumb Rubber, Sasobit, Styrene-Butadiene-Styrene (SBS), Poly-Phosphoric Acid (PPA) and Anti-Stripping Agent (ASA) 
at low temperatures $\left(-15^{\circ} \mathrm{C}\right)$. The results of their experiments indicated that the highest and the lowest fracture toughness were observed when the Crumb Rubber and ASA were used as asphalt modifiers respectively. However, one proportion of Sasobit was only used in their experiments (i.e. $2.5 \mathrm{wt} \%$ of bitumen). As an extension to their research, Aliha et al. [5] investigated the impacts of variation in factors such as asphalt modifier type, mixture air void, testing temperature and loading mode on the fracture toughness of asphalt. Their tests were performed at $-24^{\circ} \mathrm{C},-18^{\circ} \mathrm{C},-12^{\circ} \mathrm{C}$ and $-6^{\circ} \mathrm{C}$. The results of their experiments indicated that for both examined percentage of air voids (i.e. $3 \%$ and $7 \%$ ), modified asphalt mixtures demonstrated a higher fracture toughness in comparison with the unmodified mixtures. The most increase in the fracture toughness was again observed when Crumb Rubber or SBS were used. The PPA modifier did not increase the fracture toughness considerably. In a series of experiments by Kaloush et al. [12] on the asphalt mixtures modified with the Polyolefin-Aramid Compound Structural Fibers (PACSF), the impacts of this modifier on the crack propagation was investigated. The results indicated that the fiber-reinforced mix had higher resistance to crack propagation than the control mix. However, only one proportion of this material was used in their experiments (i.e. $0.045 \mathrm{wt} \%$ ), Moreover, disc-shaped specimens with $90^{\circ}$ edge cracks were used and the experiments were undertaken at $+20^{\circ} \mathrm{C}$. In a recent research by Fazaeli et al. [1], the performance of asphalt mixtures modified with Sasobit and PACSF was investigated. Their laboratory and field evaluations, based on fracture tests performed on SCB specimens at $0^{\circ} \mathrm{C}$, indicated that asphalt mixtures modified with each one or combinations of these modifiers demonstrated higher fracture toughness than the unmodified asphalt mixtures under both monotonic and cyclic loading. They observed that initiation of cracks in modified mixtures would need more stress at the crack tip area and that the cracks are progressed more slowly in the modified samples than unmodified samples. Based on these results, they concluded that the performance of modified mixtures was better than the unmodified mixtures in terms of both crack initiation resistance and the crack growth rate. More recently, Aliha et al. [13] investigated the influence of two fibers types, namely natural jute fibers and PACSF on mode I+II fracture toughness of Warm Mix Asphalt (WMA) mixtures. The experiments were conducted on the SCB specimens modified with 3 different fiber contents and at 3 different test temperatures $\left(0,-10\right.$ and $\left.-20^{\circ} \mathrm{C}\right)$. The results indicated that both fibers can increase in general the fracture resistance of WMA relative to the control mixture. This improvement was more pronounced when the testing temperature decreased or the fiber content increased. The PACSF provided better crack growth resistance characteristics and the performance of both fibers was more pronounced under mode I loading.

This literature review indicates that previous studies based on Fracture Mechanics have highly been successful in identifying many of underlying factors contributing to the fracture toughness of asphalt pavements and their deteriorations, especially at low-temperature conditions. As part of these studies, the impacts of some asphalt modifiers have also been investigated. However further researches in this area are still needed as e.g. no previous research on the impacts of asphalt modifiers such as Elastoplastomer Polymer Strings (EPS), Sulfur Polymer and Parafibers on the fracture toughness behavior of asphalt mixtures has been undertaken so far. Moreover, further researches on some of the previously examined asphalt modifiers such as Sasobit and PACSF are still needed to examine their performance under other testing conditions and/or other proportions of the modifier. Finally, the fracture energy behavior of HMA modified with these additives has received little attention in previous studies.

Thus, the objective of this research was to extend previous researches further, via examining and comparing the fracture toughness and the fracture energy behavior of HMA modified with 3 different proportions of each one of the following five asphalt modifiers. The asphalt modifiers used for this purpose were: Sulfur Polymer, Parafibers, EPS, PACSF and Sasobit. The performance of the first three materials has not previously been investigated in this respect. The previous researches on the remaining modifiers were also carried out under different experimental conditions or a limited range of modifier contents.

\begin{tabular}{cccc}
\hline Sieve size $(\mathrm{mm})$ & \multicolumn{2}{c}{ Requirement (Percent Passing) } & $\begin{array}{c}\text { Applied } \\
\text { Percentage }\end{array}$ \\
Min & 100 & Max & 100 \\
19 & 90 & 100 & 95 \\
4.75 & 44 & 100 & 57 \\
2.36 & 28 & 74 & 43 \\
0.3 & 5 & 58 & 8 \\
0.075 & 2 & 21 & 4.5 \\
\hline
\end{tabular}

Table 1: Aggregates gradation of HMA. 


\section{MATERIALS}

A $\mathrm{s}$ indicated in the previous section, five different asphalt modifiers were examined in this research. Three of these modifiers namely, EPS, Sulfur Polymer and Parafibers are produced in Iran and were provided by internal manufactures. The other two modifiers namely, PACSF and Sasobit are imported from abroad and were provided by their representative company in the country. Bitumen and aggregates were provided from a well-known local HMA production plant. The materials were then transferred to the Technical and Soil Mechanics Laboratory in Tehran which is one of the best-equipped laboratories in the fields of soil mechanics, asphalt pavement materials and cement concrete materials in Iran. The characteristics of these materials are described in the following sections.

\section{Aggregates}

Aggregates used for producing HMA fracture test samples were limestone aggregates with a nominal maximum aggregate size of $19 \mathrm{~mm}$. The aggregates gradation is indicated in Tab. 1 and it is in consistent with the grading No. 4 of Iranian Asphalt Road Pavements' Guidelines [14].

\section{Bitumen}

The base bitumen was a semi-hard bitumen with penetration grade of 60/70 and performance grade PG 64-22 in accordance with ASTM D5 / D5M-13 (2013) and ASTM D946-82 (2005) standards [15, 16]. Based on the Marshall mix design method [17], the optimum percentage of the base bitumen was identified as $4.2 \mathrm{wt} \%$ of the total HMA. For the simplicity of comparisons, all the HMA samples were produced based on this base bitumen content.

\section{PACSF}

These asphalt modifiers are comprised of compound artificial fibers such as Polyolefin fibers and Aramid fibers or similar fibers that are well known for their high strength, durability and cohesiveness. Polyolefin fibers are dissolved in the bitumen and modify its properties. On the other hand, Aramid fibers reinforce the asphalt mixture and increase its homogeneity, causing the external loads are distributed over a wider area and thereby the internal tensions are reduced in the pavement. PACSF are produced and supplied for a wide range of asphalt mixtures. The new generation of these fibers is produced and supplied in three categories for different applications including for HMA blends, Warm Mix Asphalt blends and for Patch blends.

In order to produce a more homogeneous mixture, PACSF and aggregates were initially mixed and then the bitumen was added to the mixture. In this research, the PACSF supplied for HMA blends were used. These fibers were used in three ratios namely, $0.05,0.075$ and $0.1 \mathrm{wt} \%$ of the asphalt mixture as was recommended by their supplier. The properties of the PACSF used in this research are presented in Tab. 2.

\begin{tabular}{cccccccccc}
\hline Color & $\begin{array}{c}\text { Specific } \\
\text { gravity } \\
\left(\mathrm{gr} / \mathrm{cm}^{3}\right)\end{array}$ & $\begin{array}{c}\text { Melting } \\
\text { point } \\
\left(\mathrm{C}^{\circ}\right)\end{array}$ & $\begin{array}{c}\text { Flash } \\
\text { point } \\
\left(\mathrm{C}^{\circ}\right)\end{array}$ & $\begin{array}{c}\text { Modulus } \\
\text { of } \\
\text { elasticity } \\
(\mathrm{GPa})\end{array}$ & $\begin{array}{c}\text { Tensile } \\
\text { strength } \\
(\mathrm{MPa})\end{array}$ & $\begin{array}{c}\text { Diameter } \\
(\mathrm{mm})\end{array}$ & $\begin{array}{c}\text { Length } \\
(\mathrm{mm})\end{array}$ & $\begin{array}{c}\text { Water } \\
\text { absorption }\end{array}$ & $\begin{array}{c}\text { Resistance } \\
\text { in acidic } \\
\text { and } \\
\text { alkaline } \\
\text { environ. }\end{array}$ \\
Yellow & 1.44 & 450 & - & 110 & $\begin{array}{c}\text { Aramid } \\
2800\end{array}$ & $0.02 \geq$ & 19 & No & good \\
$\begin{array}{c}\text { Cream } \\
\text { Black } \\
\text { White }\end{array}$ & $0.91-0.96$ & $\geq 120$ & $\geq 590$ & $\geq 4.2$ & $570-660$ & $0.3 \geq$ & 19 & No & Excellent \\
\hline
\end{tabular}

Table 2: Properties of applied PACSF.

\section{EPS}

In order to apply this polymer type modifier, the bitumen should initially be heated up to $155^{\circ} \mathrm{C}$ and then poured in a mixer where the modifier is gradually added to the melted bitumen. This modifier was tested in three different proportions, namely 
5,10 and $15 \mathrm{wt} \%$ of the bitumen. These percentages were selected so that the overall range recommended by its manufacture is covered. The properties of this modifier are presented in Tab. 3.

\begin{tabular}{ll}
\hline Characteristics & Description \\
\hline Form & Relatively long strings with polymer granules \\
Color & Black \\
Solubility & Homogeneously dissolves in bitumen \\
Viscosity & Increases bitumen viscosity \\
Melting point & 140 to $160^{\circ} \mathrm{C}$ \\
Chemical structure & Elastoplastomer Polymer Strings \\
\hline
\end{tabular}

Table 3: Properties of Elastoplastomer Polymer Strings.

\section{Sulfur Polymer}

The potential for application of sulfur to enhance the quality and performance of asphalt mixtures was first recognized in the 1970s but some health and environmental concerns prevented its wider applications worldwide. This led to the later initiatives by some researchers with the aim of its transformation to the sulfur compounds, using special additives, so that the resulting material can safely be used in asphalt pavements. The resulting product is called Sulphur Polymer that can partially be substituted with the bitumen content of asphalt mixtures. Sulphur Polymer is a compound material comprising sulfur as the base material combined with some other additives such as plasticizers, additives to change its melting and evaporation temperatures and also additives to prevent rapid solidification of the bitumen. This modifier should initially be dissolved in the bitumen. For this purpose, three different modified bitumen samples were produced in which 30, 40 and $50 \mathrm{wt} \%$ of the original optimum bitumen content was substituted with the Sulfur Polymer respectively. These proportions are recommended by the manufacture for application on roads with light, medium and heavy traffic loads respectively. To produce each sample, the Sulfur Polymer was dissolved in the bitumen that was previously heated up to $140^{\circ} \mathrm{C}$. The properties of the applied Sulfur Polymer in this research is presented in Tab. 4.

\begin{tabular}{ll}
\hline Characteristics & Description \\
\hline Form & Granules \\
Color & Gray \\
Solubility & Homogeneously dissolves in bitumen \\
Viscosity & Increases bitumen viscosity \\
Melting point & At least $90^{\circ} \mathrm{C}$ \\
Chemical structure & A material consisted of $90 \%$ sulfur \\
\hline
\end{tabular}

Table 4: Properties of applied Sulfur Polymer.

\section{Sasobit}

This modifier is produced by the Sasol WAX Company and it has been in the market since 1997. It is a combination of long-chain hydrocarbons produced from coal combustion using the Fischer-Tropsch process. It is usually known as Fischer-Tropsch Paraffin Wax. According to the information provided by this company, this product is a combination of chlorine, sulfur, nitrogen and oxygen atoms and it has good stability to oxidation and aging and can be stored in large quantities over a long period of time in stock.

Application of this modifier facilitates mixing and compaction capability of asphalt mixture through a reduction in the bitumen viscosity. Furthermore, it causes that a crystal structure is formed in the bitumen at low temperatures which increases its stiffness [1]. 
Sasobit is similar to the Paraffin Wax which is one of the derivations of crude oil but its molecular weight is higher than Paraffin Wax. It can easily be dissolved in the bitumen at temperatures above $120^{\circ} \mathrm{C}$ and there would be no segregation afterward. This material has a melting temperature between $70^{\circ} \mathrm{C}$ and $110^{\circ} \mathrm{C}$ and creates a homogeneous solution with bitumen. Sasobit is supplied in two physical forms namely, tablets form ( $4 \mathrm{~mm}$ diameter) and granule form ( $1 \mathrm{~mm}$ diameter). In this research, Sasobit was initially dissolved in the bitumen at $120^{\circ} \mathrm{C}$. It was then used at three different proportions namely, 2, 2.5, and $3 \mathrm{wt} \%$ of bitumen to produce HMA samples. These proportions are in the range of proportions recommended by its manufacture and are generally used in previous researches as well $[1,8,5,18,19,20]$. The properties of the Sasobit used in this research is presented in Tab. 5.

\begin{tabular}{ll}
\hline Characteristics & Description \\
Form & $\begin{array}{c}\text { Tablets form }(4 \mathrm{~mm} \text { diameter }) \text { or granules form } \\
(1 \mathrm{~mm} \text { diameter })\end{array}$ \\
Density of tablet shape (4 mm diameter) & $622 \mathrm{~kg} / \mathrm{m}^{3}$ \\
Density of granules $(1 \mathrm{~mm}$ diameter $)$ & $590 \mathrm{~kg} / \mathrm{m}^{3}$ \\
Color & Clear white \\
Solubility & Homogeneously dissolved in bitumen \\
Viscosity & Decreases bitumen viscosity \\
Melting point & $70^{\circ} \mathrm{C}$ to $110^{\circ} \mathrm{C}$ \\
Chemical structure & Coal derivatives- Hydrocarbon Aliphatic \\
\hline
\end{tabular}

Table 5: Properties of applied Sasobit.

\section{Parafibers}

Parafibers are comprised of fibers and white powders. The ratio of the powder to the fiber is pre-determined by the manufacture. It is similarly added to the asphalt mixture as the PACSF. The only difference is the percentage in which they are added to the asphalt mixture. In this research, Parafibers were used in three different proportions namely, 0.1, 0.15 and $0.2 \mathrm{wt} \%$ of the asphalt mixture to produce their corresponding samples. These proportions were selected to cover the recommended range by its manufacture. The properties of Prafiber used in this research is presented in Tab. 6.

\begin{tabular}{ll}
\hline Characteristics & Description \\
Form & Compound Fibers and powders \\
Density & $18.1 \mathrm{gr} / \mathrm{cm}^{3}$ \\
Color & White fiber and white powder \\
Powder melting point & $100{ }^{\circ} \mathrm{C}$ to $110{ }^{\circ} \mathrm{C}$ \\
Fibers melting point & $230{ }^{\circ} \mathrm{C}$ \\
Fibers length & $12-18 \mathrm{~mm}$ \\
Fibers diameter & $1.3 \mathrm{~mm}$ \\
Modulus of elasticity & $6 \mathrm{GPa}$ \\
\hline
\end{tabular}

Table 6: Properties of applied Parafibers.

\section{SAMPLES PREPARATION}

ggregates were kept overnight in an oven with its temperature set at $110^{\circ} \mathrm{C}$ and then heated for 4 hours at $160^{\circ} \mathrm{C}$ before mixing with the bitumen. Each modifier was added to asphalt mixture in accordance with the procedure described in the previous section. An asphalt mixer was used to produce a homogeneous asphalt mixture. For each 
modifier, HMA samples with $150 \mathrm{~mm}$ diameter, $130 \mathrm{~mm}$ height and mix density of $2385 \mathrm{~kg} / \mathrm{m}^{3}$ were produced in accordance with Iranian Code [14], using a gyratory compaction apparatus.

The samples were then cut into semi-circles with $30 \mathrm{~mm}$ thickness using a diamond circular saw. A saw with $1 \mathrm{~mm}$ thickness was used to create a vertical crack with $1 \mathrm{~mm}$ thickness and $20 \mathrm{~mm}$ length in the SCB specimens. Using this procedure, 8 semi-circle cracked specimen was produced for each percentage use of five examined modifiers in this research. Steps involved in the preparation of edge cracked SCB specimens are illustrated in Fig. 1.

\section{MEChanical Tests}

$\mathrm{I}$

$\mathrm{n}$ this research, the critical mode I fracture toughness $\left(\mathrm{K}_{\mathrm{IC}}\right)$ and fracture energy measures were used to get a better insight into the resistance and cracking behavior of asphalt mixtures, e.g. their crack initiation and crack propagation behavior. The value of $\mathrm{K}_{\mathrm{IC}}$ can be calculated using Eqn. (1) [9, 21, 22].

$$
\mathrm{K}_{\mathrm{IC}}=\mathrm{Y}_{\mathrm{I}} \sigma \sqrt{\pi \mathrm{a}}=\frac{\mathrm{F}_{\mathrm{f}}}{2 \mathrm{Rt}} \sqrt{\pi \mathrm{a}} \mathrm{Y}_{\mathrm{I}}(\mathrm{a} / \mathrm{R}, \mathrm{S} / \mathrm{R})
$$

where $\mathrm{K}_{\mathrm{IC}}=$ mode I fracture toughness $\left(\mathrm{MPa}^{0} \mathrm{~m}^{0.5}\right), \sigma=$ the compression stress imposed on the specimen, $\mathrm{Y}_{\mathrm{I}}=$ mode I shape factor, $\mathrm{a}=$ crack length for edge cracks or half crack length for internal cracks, $\mathrm{F}_{\mathrm{f}}=$ maximum load, $\mathrm{R}=$ Radius of Semi-Circular Bend (SCB) specimen which is described below, $\mathrm{S}=$ half of loading span and $\mathrm{t}=$ specimen thickness.

It is worth mentioning that various geometric shapes have been proposed for the specimens used in the crack propagation experiments, e.g. Single-Edge Notched Beam (SENB) [22, 23, 24], Cracked Straight Through Brazilian Disc (CSTBD) or Brazilian Disc (BD) [22, 25], Disc-shaped Compact Tension (DCT) [26, 27, 28], Edge Notched Disc Bend (ENDB) [29, 30, 31] and Semi-Circular Bend (SCB) [21, 3, 32, 4, 33, 34] specimens. Among these specimen shapes, the SCB specimens have widely been used by many researchers. This is largely due to its simple geometry, ease of sample preparation from the gyratory compactor or from the field, the possibility of creating a wide range of loading modes in this specimen, ease of loading, etc. A schematic view of SCB specimen under mode I loading is indicated in Fig. 2.
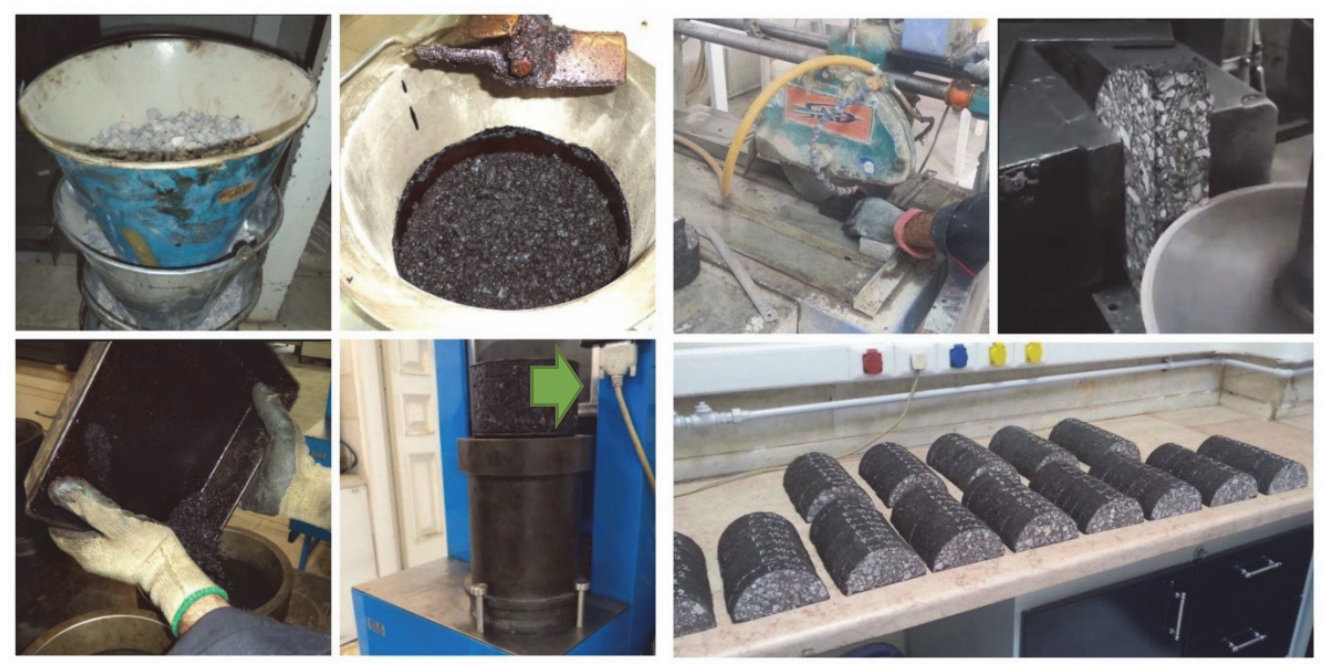

Figure 1: Steps involved to produce edge cracked SCB specimens.

In order to establish the LEFM conditions for both normal and modified mixtures and also use similar temperature during the experiments, the specimens were kept in a freezer with $-15^{\circ} \mathrm{C}$ temperature for 6 hours. This temperature is similarly used in a number previous researches on fracture resistance of HMA at low temperatures $[9,2,5,7]$. This temperature is also in the range recommended by the AASHTO provisional specification for determining the fracture energy of asphalt mixtures using the SCB geometry which requires that these tests are performed at less than $10^{\circ} \mathrm{C}$ above the PG lower limit of the base bitumen used in the experiments [35]. PG lower limit corresponds to the minimum pavement design temperature in the Superpave Performance Grading system. Each specimen was then laid on the supports so that the distance between 
two support points was $100 \mathrm{~mm}$ and the crack was situated in the middle. A UTM device with the loading capacity of 15 $\mathrm{KPa}$ was used for loading of the specimens. In order to minimize the effects of temperature variations, the setting and loading process of the specimens was carried out rapidly and a temperature controlled chamber was used.
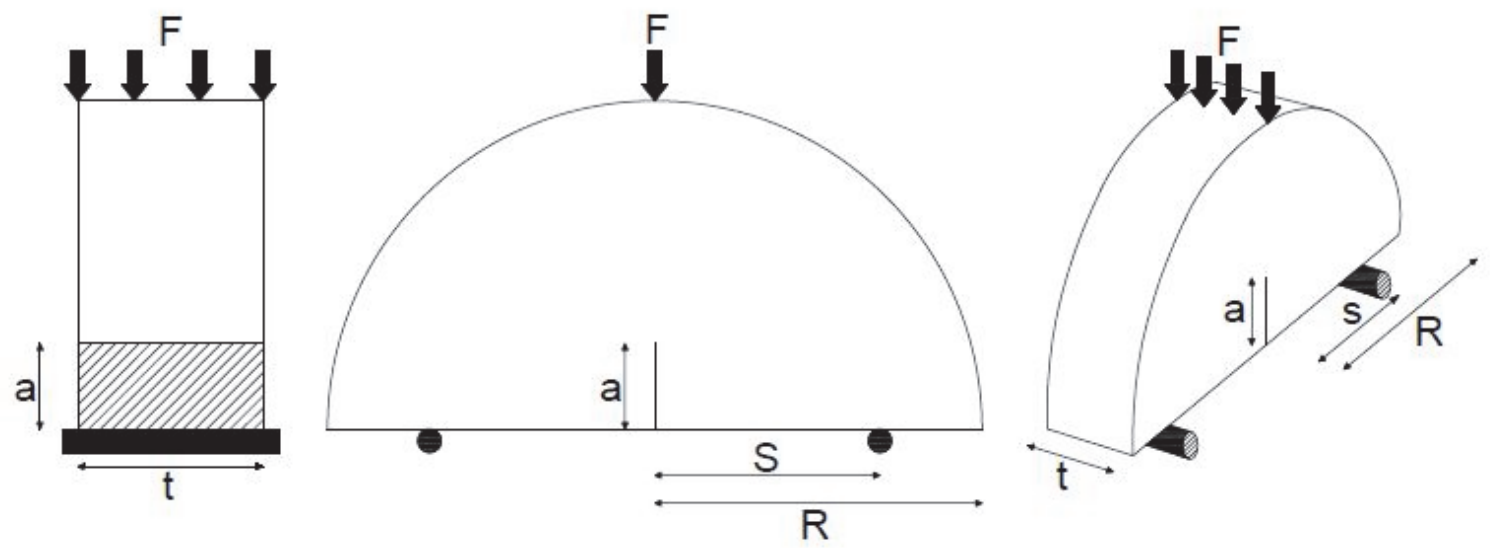

Figure 2: Schematic view of edge cracked SCB specimen under mode I loading.

$\mathrm{Li}$ and Marasteanu [4] in their research noticed that loading rate would have an influence on the fracture energy, i.e. the fracture energy decreases with an increase in loading rate at different temperatures. However this reduction in fracture energy was found to be more pronounced at higher test temperatures (e.g. $-6^{\circ} \mathrm{C}$ and above), whereas the effect due to loading rate on the fracture energy was mostly diluted at lower temperatures (e.g. $-18^{\circ} \mathrm{C}$ or $-30^{\circ} \mathrm{C}$ ).

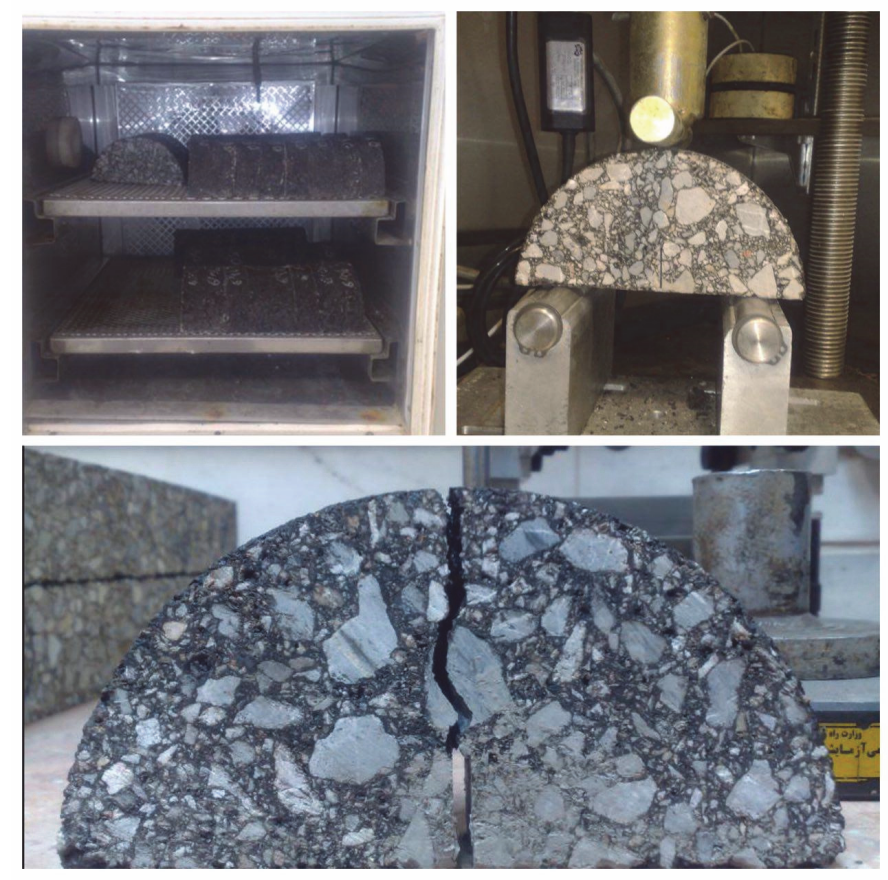

Figure 3: Crack propagation testing process.

In this study, a load line displacement rate of 3 millimeters displacement per minute was applied as this rate has also been used in a number of similar researches $[1,2,8,13]$. These arrangements for temperature control and loading speed were used to ensure that the experiments have been conducted under LEFM conditions. An illustration of the process involved during these experiments is presented in Fig. 3. 
The maximum load for each sample was obtained from its corresponding load-displacement diagram (e.g. see from Fig. 4 to Fig.9). The fracture toughness for each specimen was then calculated using Eqn. (1). The assumed values for the parameters used in this equation are $a=20 \mathrm{~mm}, \mathrm{R}=75 \mathrm{~mm}, \mathrm{t}=30 \mathrm{~mm}, \mathrm{~S}=50 \mathrm{~mm}$, and $\mathrm{Y}_{\mathrm{I}}=3.73$. The shape factor value was obtained from previous research by Ameri et al. [3].

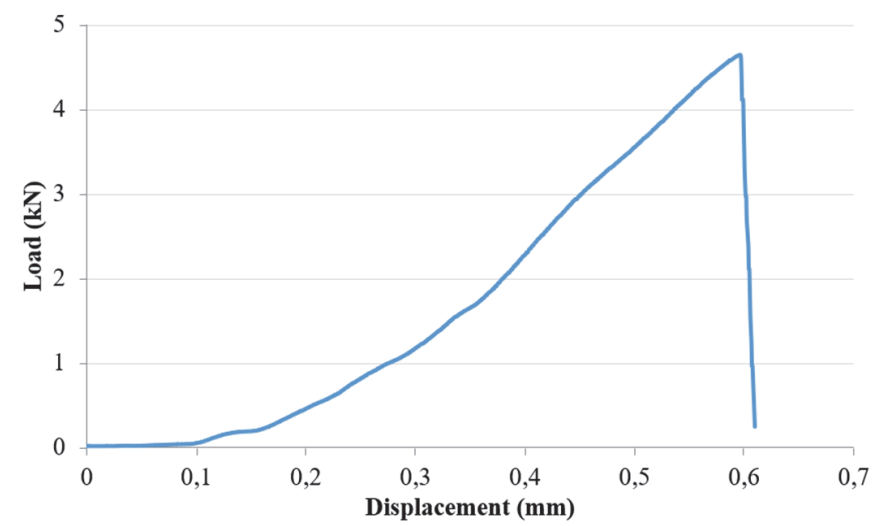

Figure 4: A load-displacement curve obtained for the Control SCB test sample.

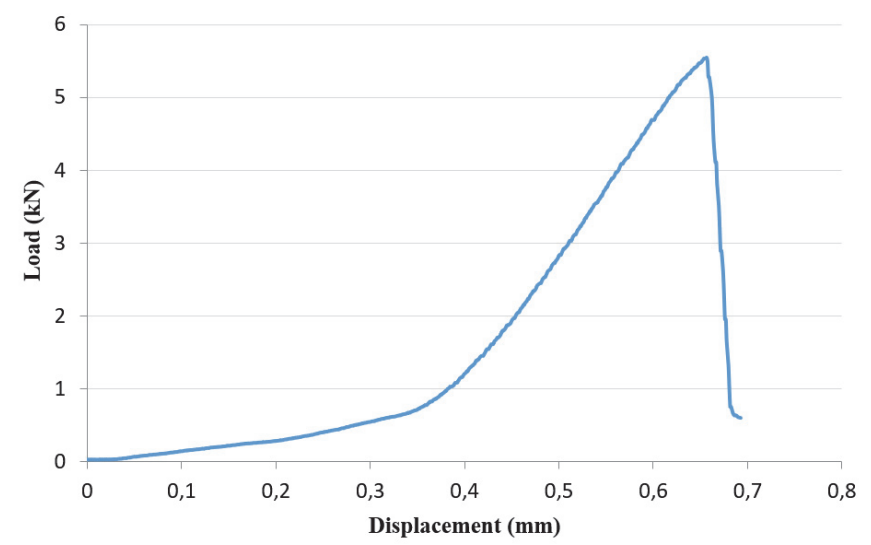

Figure 6: A load-displacement curve obtained for the SCB test sample modified with $\underline{\text { Sulfur } 50 .}$.

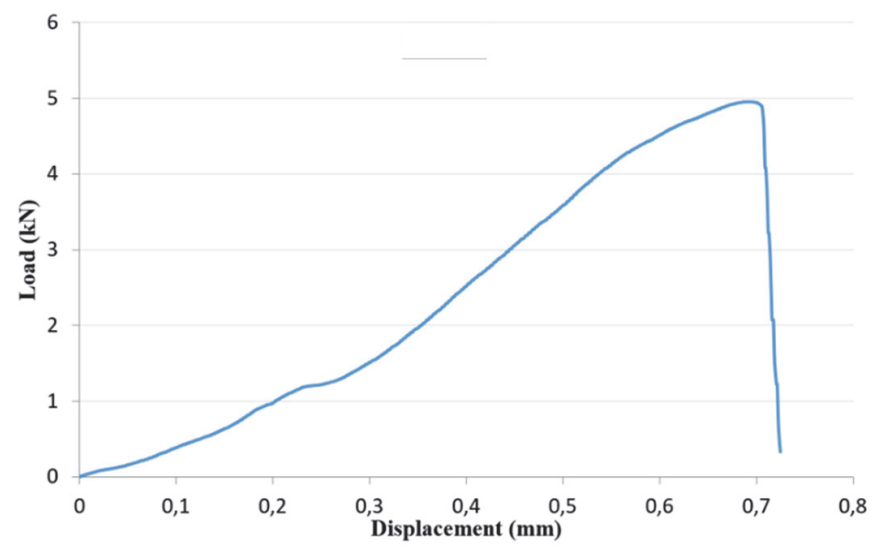

Figure 8: A load-displacement curve obtained for the SCB test sample modified with EPS 15.

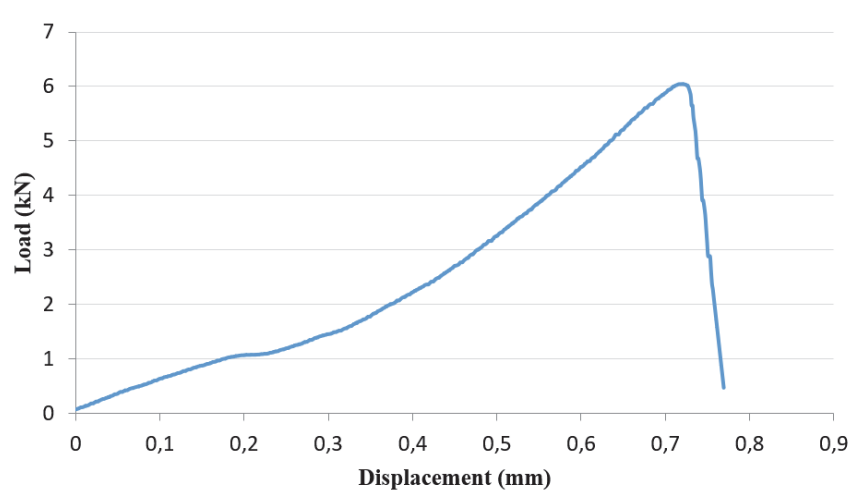

Figure 5: A load-displacement curve obtained for the SCB test sample modified with $\underline{\text { Sasobit } 3}$.

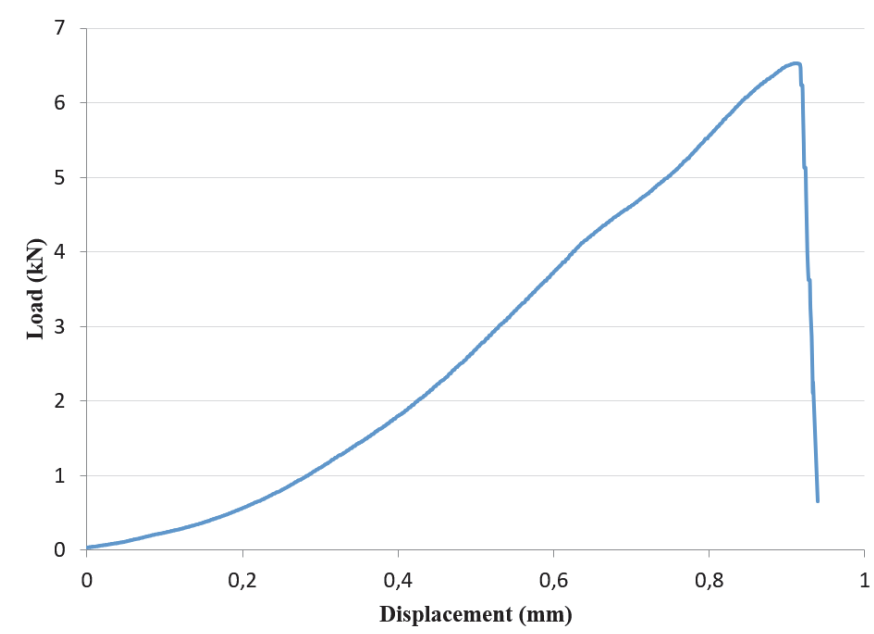

Figure 7: A load-displacement curve obtained for the SCB test sample modified with PACSF 0.1.

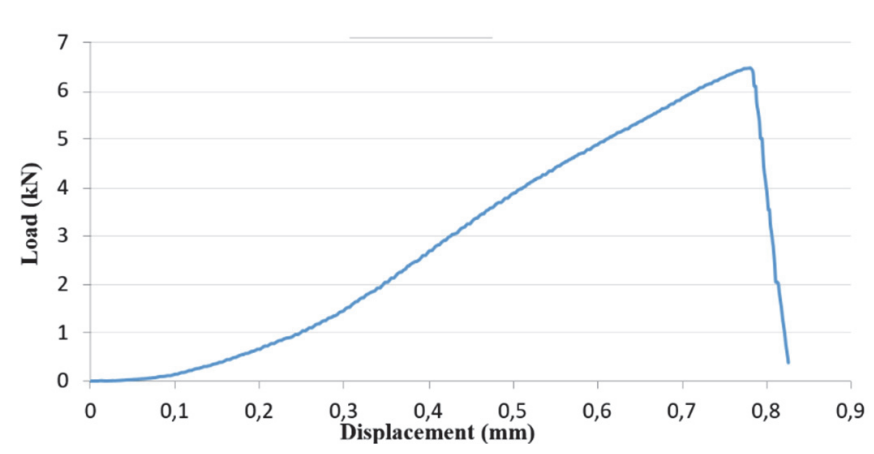

Figure 9: A load-displacement curve obtained for the SCB test sample modified with Parafiber 0.2. 
The fracture energy is equal to the area under the load-displacement curve divided by the effective area of the fracture. It implies that a specimen with higher fracture energy capacity would absorb higher energy before reaching to the fracture point. It can be calculated using Eqn. (2) below.

$$
G_{f}=\frac{W_{f}}{A_{\text {lig }}}
$$

where $G_{f}, W_{f}$ and $A_{\text {lig }}$ are fracture energy, work to breakdown a specimen or the area under the load- displacement curve and ligament area, respectively.

\begin{tabular}{|c|c|c|c|c|c|c|}
\hline \multirow{2}{*}{$\begin{array}{l}\text { Modified/Unmodified } \\
\text { HMA Specimen Type }\end{array}$} & \multicolumn{3}{|c|}{ Fracture Toughness of Specimens } & \multicolumn{3}{|c|}{ Fracture Energy of Specimens } \\
\hline & 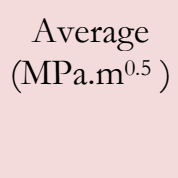 & $\begin{array}{l}\mathrm{COV} \\
(\%)\end{array}$ & $\begin{array}{c}\text { \% Change } \\
\text { modified } \\
\text { versus } \\
\text { control }\end{array}$ & $\begin{array}{l}\text { Average } \\
\left(\mathrm{J} / \mathrm{m}^{2}\right)\end{array}$ & $\begin{array}{l}\mathrm{COV} \\
(\%)\end{array}$ & $\begin{array}{c}\% \text { Change } \\
\text { modified } \\
\text { versus } \\
\text { control }\end{array}$ \\
\hline Unmodified (control) & 0.965 & 4.9 & - & 931 & 13.1 & - \\
\hline PACSF 0.05 & 1.187 & 15.1 & 22.28 & 1228 & 8.7 & 31.79 \\
\hline PACSF 0.075 & 1.308 & 11.5 & 35.55 & 1350 & 15.1 & 44.95 \\
\hline PACSF 0.1 & 1.356 & 6.8 & 40.4 & 1430 & 4.3 & 53.48 \\
\hline Sulfur Polymer 30 & 0.974 & 16.2 & 1 & 969 & 5.3 & 4.07 \\
\hline Sulfur Polymer 40 & 1.087 & 6.6 & 11.74 & 1007 & 2.4 & 8.15 \\
\hline Sulfur Polymer 50 & 1.152 & 8.4 & 24.14 & 1061 & 3.7 & 13.87 \\
\hline EPS 5 & 0.957 & 13 & -1 & 1036 & 6.4 & 11.22 \\
\hline EPS 10 & 0.935 & 8.4 & -3.3 & 1063 & 2.5 & 14.15 \\
\hline EPS 15 & 1.029 & 8.8 & 6.63 & 1125 & 3.1 & 20.73 \\
\hline Parafiber 0.1 & 1.140 & 8.1 & 13.98 & 1212 & 2.5 & 30.09 \\
\hline Parafiber 0.15 & 1.254 & 9.7 & 25.38 & 1303 & 5.1 & 39.88 \\
\hline Parafiber 0.2 & 1.344 & 10.3 & 36.78 & 1387 & 3.4 & 48.93 \\
\hline Sasobit 2 & 1.084 & 6.2 & 12.33 & 1100 & 7.5 & 18.13 \\
\hline Sasobit 2.5 & 1.156 & 8.9 & 19.84 & 1175 & 7 & 26.14 \\
\hline Sasobit 3 & 1.256 & 7.6 & 30.21 & 1279 & 2.6 & 37.37 \\
\hline
\end{tabular}

Table 7: Average, COV and \% change values of the fracture toughness and fracture energy for each specimen type.

\section{ANALYSIS OF RESULTS AND DISCUSSION}

ollowing the experiments, the average and covariance (COV) values of the measured fracture toughness and fracture energy for specimens with similar modifier type and proportion were calculated. Also, the percentage increase in the average fracture toughness of each specimen type in comparison with the control specimen (the similar specimen 
when no modifier is added) was calculated. The results are presented in Tab. 7, Fig. 10 and Fig. 11. As indicated in Tab. 7, the COV values of fracture toughness and fracture energy for all specimen types is less than $25 \%$, indicating the repeatability of experiments. Fig. 10 indicates the observed average fracture toughness of specimens in ascending order from top to bottom. The suffix numbers assigned to each modifier type represent the percentage of applied modifier.

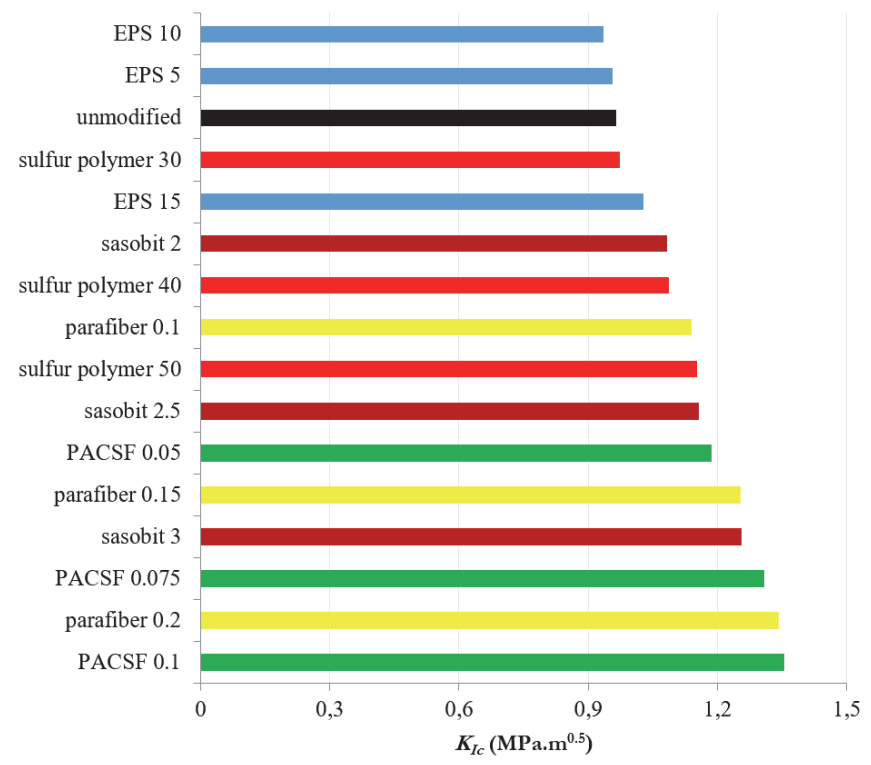

Figure 10: Bar chart of average fracture toughness of specimens.

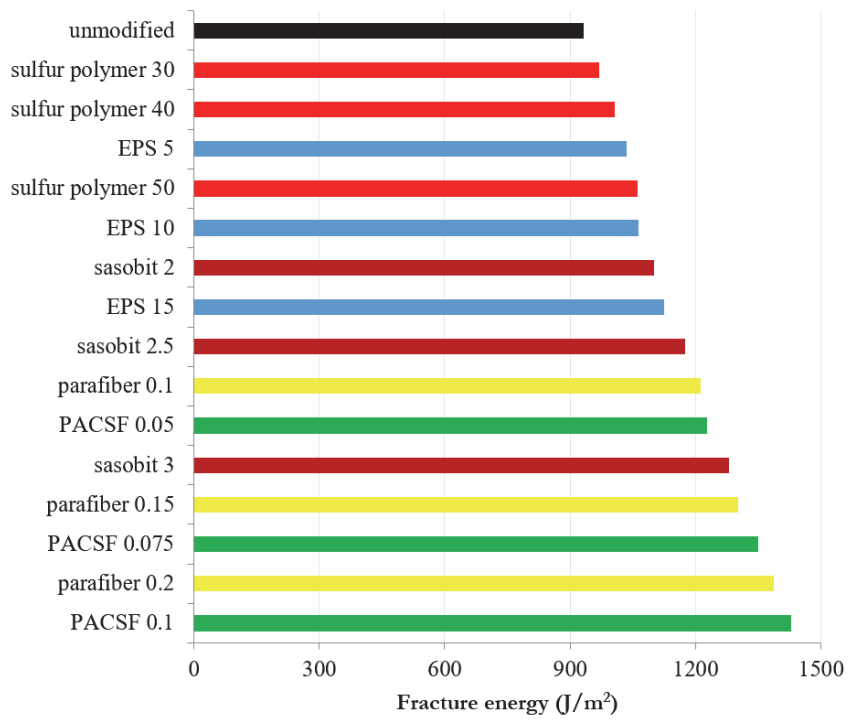

Figure 11: Bar chart of average fracture energy of specimens.

The results indicate that specimens modified with PACSF have produced the highest fracture toughness. This performance has been closely followed by specimens modified with Parafibers. This behavior can be attributed to the fact that these modifier types not only modify the bitumen but also reinforce the asphalt mixture, causing the loads are distributed over a wider area and thereby the overall tensions are reduced. This would result in a better performance for the asphalt pavements during their operational life. The results for the specimens modified with the EPS indicates that the fracture toughness initially decreased when the two lower proportions of this modifier namely, $5 \%$ and $10 \%$ were used. The fracture toughness then slightly increased when the proportion of this modifier was increased to $15 \%$. This indicates that the asphalt mixtures modified with this modifier may produce inconsistent behavior under different percentage usage of this modifier. This behavior may be attributed to the chemical structure of this modifier and its reaction with the bitumen. However, further research is needed to explore the underlying causes of this behavior. The results for the specimens modified with other four modifier types indicates that the fracture toughness has consistently increased with an increase in the proportion of the modifier.

In respect with the fracture energy, the results presented in Tab. 7 and Fig. 11 indicate that the fracture energy has also consistently increased with an increase in the proportion of each modifier type. These results also indicate that specimens modified with PACSF and Prafibers have produced the highest fracture energy respectively. These results are in consistent with the results of the fracture toughness tests on the specimens. This performance can be attributed to the reinforcing effect of fibers in these two modifiers which would increase the ductility of their corresponding asphalt mixtures. This would extend their energy absorbance capacity before reaching to the ultimate fracture point.

The results also indicate that the fracture energy of the specimens modified with EPS has increased consistently as the percentage of these modifiers was increased from 5 to $15 \%$. This is in contrast with the behavior observed for the fracture toughness of specimens modified with this modifier. Furthermore, the results indicate that increase in the fracture energy of specimens modified with different types and contents of modifiers has not followed the same order observed for the fracture toughness (e.g. compare Fig. 10 and Fig. 11). These results indicate that the performance of examined modifiers in terms of fracture toughness and fracture energy could be different, especially when different proportion of modifiers are used. However, the results presented in Tab. 7, Fig. 10 and Fig. 11 show that if we only consider the highest observed values for each modifier type and exclude the results for the specimens modified with EPS, the order of increase in both fracture toughness and fracture energy for asphalt mixtures modified with other four remaining modifiers has been 
consistent. According to these results, the order of increase in both measures under the highest applied proportion of modifiers has been: Sulfur Polymer 50, Sasobit 3, Parafiber 0.2 and PACSF 0.1, respectively.

The relationship between the observed average fracture toughness and fracture energy of similar asphalt mixtures tested in this study is presented in Fig. 12 which indicates a high correlation between the variation of these two measures $\left(\mathrm{R}^{2}=0.849\right)$. This figure indicates a strong and direct relationship between energy absorbance capability of modified asphalt mixtures and their fracture toughness when they are subjected to mode I loading at $-15^{\circ} \mathrm{C}$ temperature.

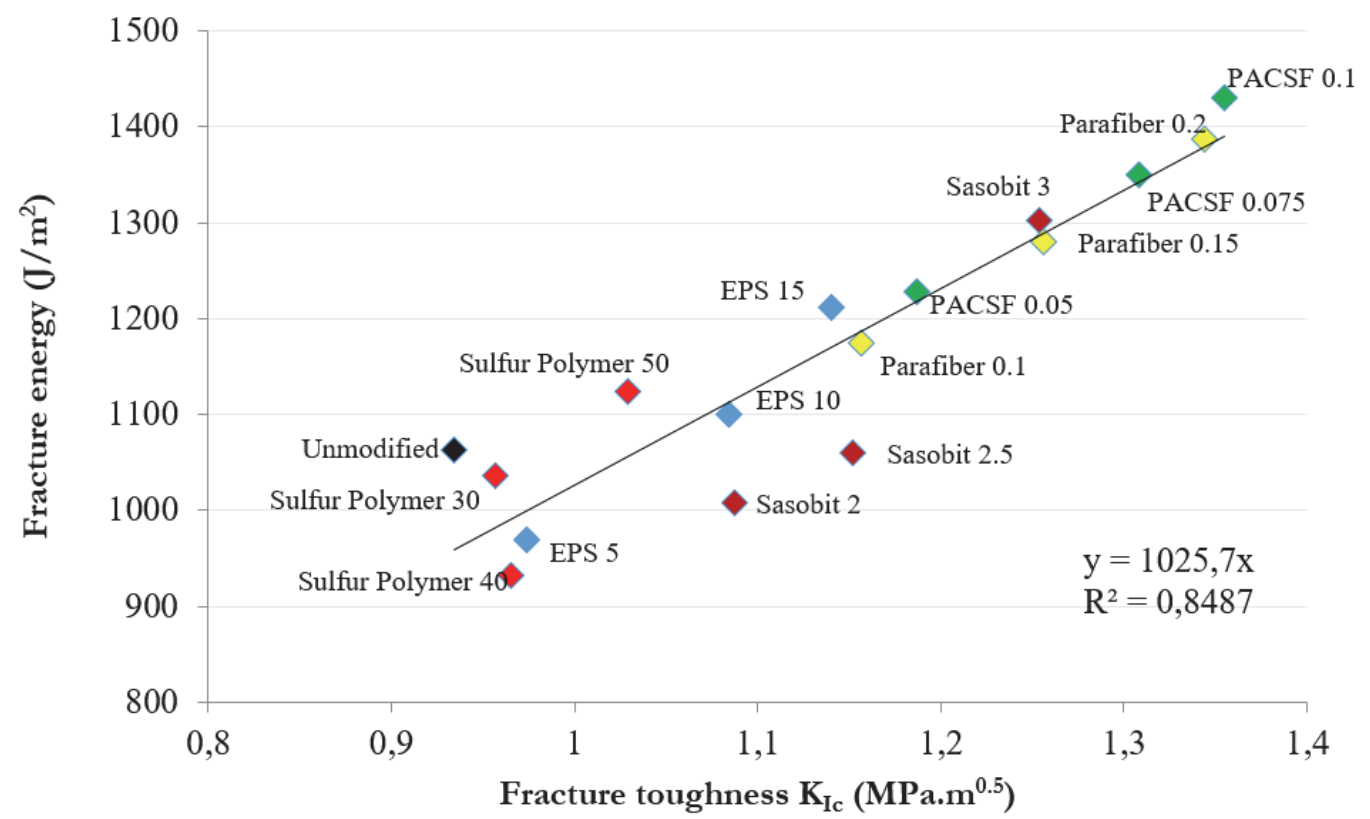

Figure 12: The relationship between the observed average fracture energy and fracture toughness of modified and unmodified asphalt mixtures.

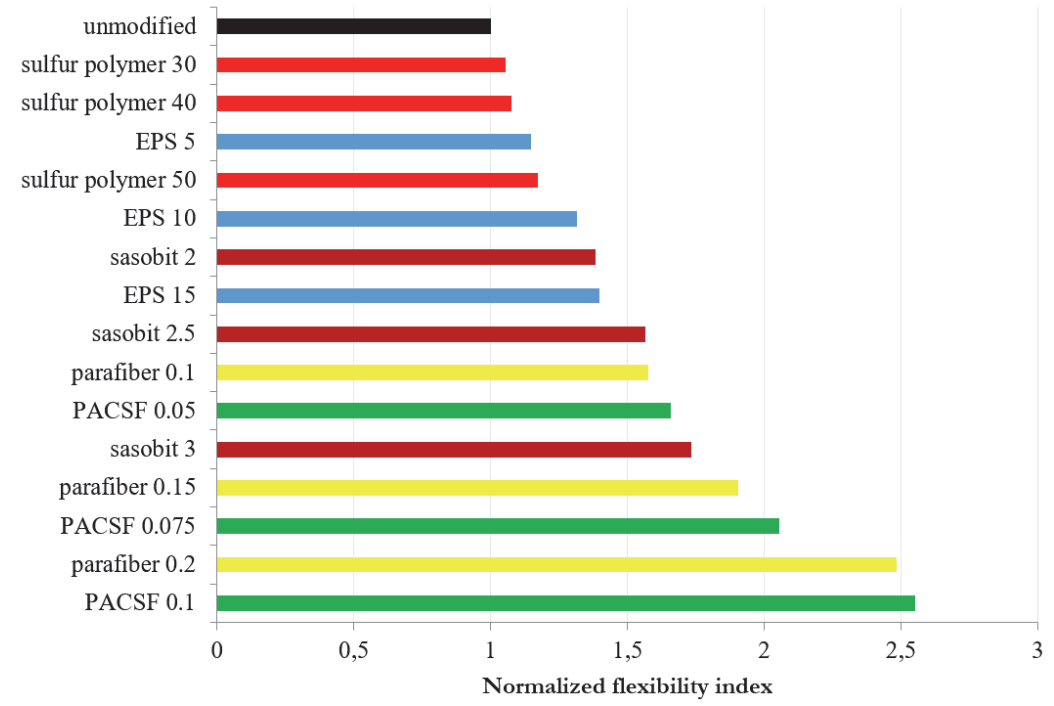

Figure 13: Flexibility Index of modified asphalt mixtures, normalized in relation to the unmodified mixture

It could be argued that although the results indicate an increase in the fracture toughness and fracture energy of the modified asphalt mixtures but increase in toughness may be attributed to the increased viscosity and stiffness of the binder. Furthermore, the fracture energy can mask the brittleness if it is very strong. Therefore, the resulting brittleness can prolong the crack initiation but can accelerate the crack propagation afterward. In order to investigate whether the modified asphalt mixtures examined in this study possess both strength and ductility, a fracture based Flexibility Index (FI) proposed by Ozer 
et al. [36] was also calculated for the modified and control asphalt mixtures. In this measure, the combination of post-peak slope of load-displacement curve and the fracture energy is used for characterizing the cracking potential of asphalt mixtures in addition to the fracture toughness. The FI was calculated using Eqn. (3) as suggested by them [36].

$$
F I=\frac{G_{f a}}{a b s(m)}
$$

Where: $G_{\mathrm{fa}}$ denotes fracture energy reported in $\mathrm{J} / \mathrm{m}^{2}$ and $\mathrm{abs}(\mathrm{m})$ denotes the absolute value of the post-peak slope of the load-displacement diagram reported in $\mathrm{kN} / \mathrm{mm}$.

The results are illustrated in Fig. 13 which indicates that the normalized Flexibility Index of modified mixtures is more than 1 , indicating the higher flexibility of modified asphalt mixtures in comparison with the unmodified asphalt mixture. This increase is less pronounced for asphalt mixtures modified with low and average proportions of Sulfur Polymer (i.e. 5\% and 8\% respectively). A comparison of Fig. 11 and Fig. 13 indicates that the order of increase in the normalized FI of tested modifiers in accordance with their type and proportion are consistently similar with the fracture energy results. According to these results, it could then be expected that these modifiers would not only improve crack initiation resistance of asphalt mixtures but also their crack growth at temperatures as low as $-15^{\circ} \mathrm{C}$.

\begin{tabular}{|c|c|c|c|c|c|}
\hline $\begin{array}{l}\text { HMA Specimen } \\
\text { Type }\end{array}$ & $\begin{array}{c}\text { B } \\
\% \text { Change in } \\
\text { Fracture } \\
\text { Toughness } \\
\text { (modified vs } \\
\text { control) }\end{array}$ & $\begin{array}{c}\text { C } \\
\% \text { Change in } \\
\text { Fracture } \\
\text { Energy } \\
\text { (modified vs } \\
\text { control) }\end{array}$ & $\begin{array}{c}\mathrm{D} \\
\% \text { Change in } \\
\text { costs } \\
\text { (US\$) }\end{array}$ & $\mathrm{B} / \mathrm{D}$ ratio & $\mathrm{C} / \mathrm{D}$ ratio \\
\hline $\begin{array}{l}\text { Unmodified } \\
\text { (control) }\end{array}$ & - & - & - & - & - \\
\hline PACSF 0.05 & 22.28 & 31.79 & 12.6 & 1.8 & 2.5 \\
\hline PACSF 0.075 & 35.55 & 44.95 & 18.9 & 1.9 & 2.4 \\
\hline PACSF 0.1 & 40.4 & 53.48 & 25.2 & 1.6 & 2.1 \\
\hline Sulfur Polymer 30 & 1.0 & 4.07 & 1.2 & 0.8 & 3.4 \\
\hline Sulfur Polymer 40 & 11.74 & 8.15 & 1.6 & 7.3 & 5.1 \\
\hline Sulfur Polymer 50 & 24.14 & 13.87 & 2.2 & 11.0 & 6.3 \\
\hline EPS 5 & -1.0 & 11.22 & 4.9 & -0.2 & 2.3 \\
\hline EPS 10 & -3.3 & 14.15 & 9.9 & -0.3 & 1.4 \\
\hline EPS 15 & 6.63 & 20.73 & 14.8 & 0.4 & 1.4 \\
\hline Parafiber 0.1 & 13.98 & 30.09 & 7.1 & 2.0 & 4.2 \\
\hline Parafiber 0.15 & 25.38 & 39.88 & 10.6 & 2.4 & 3.8 \\
\hline Parafiber 0.2 & 36.78 & 48.93 & 14.1 & 2.6 & 3.5 \\
\hline Sasobit 2 & 12.33 & 18.13 & 6.5 & 1.9 & 2.8 \\
\hline Sasobit 2.5 & 19.84 & 26.14 & 8.1 & 2.4 & 3.2 \\
\hline Sasobit 3 & 30.21 & 37.37 & 9.7 & 3.1 & 3.9 \\
\hline
\end{tabular}

Table 8: Summary of the economic assessment of modified asphalt mixtures.

It could also be argued that the application of modifiers could accelerate crack growth at low temperatures, provided that the temperature of modified bitumen drops below its glass transition temperature $\left(\mathrm{T}_{g}\right)$ which is a transition point from softening quasi-brittle to brittle behavior. This behavior could be attributed to the fact that the bitumen strength and its adhesion to the aggregates would initially be increased with a decrease in the bitumen temperature but below a certain temperature (i.e. $T_{g}$ ), accumulation of microcracks in the bitumen caused by its increased stiffness and brittleness, leads to reductions in the fracture toughness of the mixture as suggested by [6] as well. In this study, the results suggest that the examined modifiers have not increased the glass transition temperature or the lower PG limit of modified bitumens above the test temperature $\left(-15^{\circ} \mathrm{C}\right)$. It is worth mentioning that the $\mathrm{T}_{\mathrm{g}}$ of neat bitumens is also around $-15^{\circ} \mathrm{C}[37,38]$ and a lower $\mathrm{T}_{\mathrm{g}}$ for the modified bitumens used in this study is expected.

The results may also imply that the lower PG limit of the modified bitumens in this study is still below the test temperature $\left(-15^{\circ} \mathrm{C}\right)$. In a previous research by Aliha et al. [7], the performance grade of a neat bitumen similar to one used in this study 
(penetration grade 60/70 and PG 64-22), when modified with 2.5\%wt Sasobit, was measured as 70-22, indicating no change in the lower PG limit of this modified bitumen.

In future researches, this study can further be elaborated to provide a more in-depth understanding of the underlying mechanisms behind the cracking performance of these modifiers, to investigate the chemical and rheological characterization of these modifiers and their corresponding modified binders.

The results of an economic assessment of the modifiers examined in this study is presented in Tab. 8. For this assessment, the cost of HMA was obtained from its average bid prices in the USA (i.e. $\$ 85$ per ton [39]). The cost of modifiers was obtained from their representative companies. The following conclusions may be drawn from these results:

- The additional costs associated with using these modifiers varies in the range of 1.3 to $25.2 \%$, depending on the type and the proportion of modifiers. The highest cost increase is associated with the PACSF modifier and the lowest cost increase is related to the Sulfur Polymer.

- The ratios of percentage changes in the fracture toughness and fracture energy to the percentage change in their corresponding modified HMA costs presented in Tab. 8 (B/D and C/D ratios) indicate that Sulfur Polymer has produced the most effective results in economic terms. However, this is compromised by much less improvement in the fracture toughness and fracture energy measures in comparison with PACSF, Parafiber and Sasobit modifiers.

- In highway projects with the tight budgets, it may be advisable to apply Parafiber and Sasobit to provide a balance between the fracture performance and the costs. However when the cost is not an important issue, PACSF would be the best choice.

\section{CONCLUSIONS}

- The results of fracture toughness and fracture energy experiments on the SCB specimens, produced from HMA modified with 5 different asphalt modifiers, using three different proportions for each, indicated that overall both measures were improved in comparison with similar but unmodified HMA specimens. The results indicated that with an increase in the proportion of each modifier in the bitumen, both fracture toughness and fracture energy were increased. The only exception was for the specimens containing 5 and $10 \mathrm{wt} \%$ EPS in which the fracture toughness was reduced.

- The results indicated that the fracture toughness and fracture energy of SCB specimens modified with two modifiers containing fiber components namely, PACSF and Parafibers, in comparison with other three modifiers were highest respectively. The increase in the fracture toughness of these specimens can be attributed to the role of reinforcement fibers in producing a more integrated structure and thereby reducing the tensions in the specimens through wider distribution of loads. The increase in the fracture energy of these specimens can be attributed to the role of reinforcement elements in increasing the ductility and energy absorbance of the asphalt mixture. The other three modifiers would mainly improve the bitumen properties.

- The other three modifiers in their descending order of increased fracture toughness were Sasobit, Sulfur Polymer and EPS respectively, when their highest modifier content was used in the asphalt mixture.

- The other three modifiers in their descending order of increased fracture energy were Sasobit, EPS and Sulfur Polymer respectively, when their highest modifier content was used in the asphalt mixture.

- If we exclude the performance of the HMA modified with EPS, the other four remaining additives, under their highest percentage usage, demonstrated a similar order of performance in terms of both fracture toughness and fracture energy.

- A higher Flexibility Index measured for modified asphalt mixtures in comparison with similar but unmodified asphalt mixtures indicated that their ductility has not been compromised. It is therefore expected that these modifiers would enhance crack initiation resistance and crack growth behavior of asphalt mixtures at low temperatures.

- A combined economic-performance based analysis indicated that depending on the extent of required improvement in the fracture behavior of HMA and available budget, the choice of appropriate modifier could be different.

\section{ACKNOWLEDGMENT}

1

he authors would like to express their gratitude to the General Directorate of Roads and Urban Development of Yazd Province in Iran for providing the financial support of this study. 


\section{DECLARATION OF INTEREST}

he authors declare that they have no commercial or financial interest in the materials discussed in this manuscript.

\section{REFERENCES}

[1] Fazaeli, H., Samin, Y., Pirnoun, A. and Dabiri, A.S.( 2016). Laboratory and field evaluation of the warm fiber reinforced high-performance asphalt mixtures (case study Karaj - Chaloos Road), Construction and Building Materials, 122, pp. 273-283.

[2] Aliha, M.R.M. and Fattahi Amirdehi, H.R. (2016). Fracture toughness prediction using Weibull statistical method for asphalt mixtures containing different air void contents, Fatigue \& Fracture of Engineering Materials \& Structures, 40 (1), pp. 55-68.

[3] Ameri, M., Mansourian, A., Pirmohammad, S., Aliha, M.R.M. and Ayatollahi, M.R. (2012). Mixed mode fracture resistance of asphalt concrete mixtures, Engineering Fracture Mechanics, 93, pp. 153-167.

[4] Li, X.J., Marasteanu, M.O. (2010). Using semi-circular bending test to evaluate low-temperature fracture resistance for asphalt concrete, Experimental Mechanics, 50, pp. 867-876.

[5] Aliha, M.R.M., Behbahani, H., Fazaeli, and Rezaifar, H. M.H. (2015). Experimental study on the mode I fracture toughness of different asphalt mixtures, Scientia Iranica, 22, pp. 120-130.

[6] Pirmohammad, S., Ayatollahi, M.R. (2014). Fracture resistance of asphalt concrete under different loading modes, Construction and Building Materials, 53, pp. 235-242.

[7] Aliha, M.R.M., Fazaeli, H. Aghajani, S. and Moghadas Nejad, F. (2015). Effect of temperature and air void on mixed mode fracture toughness of modified asphalt mixtures, Construction and Building Materials, 95, pp. 545-555.

[8] Aliha, M.R.M., Behbahani, H. Fazaeli and H. Rezaifar, M.H. (2014). Study of characteristic specification on mixed mode fracture toughness, Construction and Building Materials, 54, pp. 623-635.

[9] Behbahani, H., Aliha, M.R.M., Fazaeli, H. and Aghajani, S. (2013). Experimental fracture toughness study for some modified asphalt mixtures, Advanced Materials Research, 723, pp. 337-334.

[10] Ren, J. and Sun, L. (2017). Characterizing air void effect on fracture of asphalt concrete at low- temperature using discrete element method, Int. Journal of Engineering Fracture Mechanics, 170, pp. $23-43$.

[11] Saha , G. and Biligiri, K.P. (2016). Fracture properties of asphalt mixtures using semi-circular bending test: A state-ofthe-art review and future research, Construction and Building Materials, 105, pp. 103-112.

[12] Kaloush, K.E., Zeiada, W.A., Biligiri K.P., Rodezno, M.C.and Reed, J. (2010). Evaluation of fiber-reinforced asphalt mixtures using advanced material characterization tests, Journal of Testing and Evaluation, 38, pp. 400-411.

[13] Aliha,M.R.M., Razmi, A. and Mansourian, A. (2017). The influence of natural and synthetic fibers on low temperature mixed mode I + II fracture behavior of warm mix asphalt (WMA) materials, Int. Journal of Engineering Fracture Mechanics, 182, pp. 322-336.

[14] Iranian Planning and Management Organization. (2011). Iranian Asphalt Road Pavement Regulations, Code No. 234, Tehran, Iran.

[15] ASTM International. (2013). ASTM D5 / D5M-13, Standard Test Method for Penetration of Bituminous Materials, ASTM International, West Conshohocken, PA, www.astm.org.

[16] ASTM Standard (2005). ASTM D946-82, Standard for Penetration-Graded Asphalt Cement for Use in Pavement Construction, ASTM International, West Conshohocken, PA, www.astm.org

[17] ASTM International (2015). ASTM D6927-15, Standard Test Method for Marshall Stability and Flow of Asphalt Mixtures, ASTM International, West Conshohocken, PA, www.astm.org

[18] Fallah Tafti, M., Khabiri, M.M. and Khani Sanij, H. (2016). Experimental investigation of the effect of using different aggregate types on WMA mixtures, International Journal of Pavement Research and Technology, 9, pp. 376-386.

[19] Li, X., Zhou, Z. and You, Z. (2016). Compaction temperatures of sasobit produced warm mix asphalt mixtures modified with SBS, Construction and Building Materials, 123, pp. 357-364.

[20] Fazaeli, H., Behbahani, H., Amini, A.A., Rahmani, J. and Yadollahi, G. (2012). High and low temperature properties of FT-paraffin-modified bitumen, Advances in Materials Science and Engineering. DOI:10.1155/2012/406791. 
[21] Ayatollahi, M.R. and Aliha, M.R.M. (2007). Wide range data for crack tip parameters in two disc-type specimens under mixed mode loading, Computational Materials Science, 38, pp. 660-670.

[22] Mansurian, A. and Ayatollahi, M.R. (2012). Crack growth behavior in asphalt under the tensile- shear combination loads (in low temperature), Tehran: Transportation Research Institute of Iran University of Science and technology.

[23] Braham, A., Buttlar, W. and Ni , F. (2010). Laboratory mixed- mode cracking of asphalt concrete using the single- edge notch beam, Road Materials and Pavement Design, 11, pp. 947-968.

[24] Wagoner, M.P., Buttlar, W.G. and Paulino, G.H. (2005). Development of a single-edge notched beam test for asphalt concrete mixtures, Journal of Testing and Evaluation, 33, pp. 452-460.

[25] Ayatollahi, M.R. and Aliha, M.R.M. (2008). On the use of Brazilian disc specimen for calculating mixed mode I-II fracture toughness of rock materials, Engineering Fracture Mechanics, 75(16), pp. 4631-4641.

[26] Wagoner, M.P., Buttlar, W.G., Paulino, G.H. and Blankenship, P. (2005). Investigation of the fracture resistance of hotmix asphalt concrete using a disk- shaped compact tension test, Transportation Research Records, 1929, pp. 183-192.

[27] Kim, H., Wagoner, M.P.and Buttlar, W.G. (2009). Numerical fracture analysis on the specimen size dependency of asphalt concrete using a cohesive softening model, Construction and Building Materials, 23, pp. 2112-2120.

[28] Behnia, B., Dave, E.V., Ahmed, S., Buttlar, W.G. and Reis, H. (2011). Effects of recycled asphalt pavement amounts on the low-temperature cracking performance of asphalt mixtures using acoustic emissions, Transportation Research Record, 2208, pp. 64-71.

[29] Aliha, M.R.M., Bahmani, A. and Akhondi, S. (2014). Numerical analysis of a new mixed mode I/III fracture test specimen, Engineering Fracture Mechanics, 134, pp. 95-110.

[30] Aliha, M.R.M., Bahmani, A., Akhondi, Sh. (2015). Determination of mode III fracture toughness for different materials using a new designed test configuration, Materials \& Design, 86, pp. 863-871.

[31] Aliha, M.R.M., Bahmani A. and Akhondi, S. (2016). A novel test specimen for investigating the mixed mode I/III fracture toughness of hot mix asphalt composites- Experimental and the oretical study, International Journal of Solids and Structures, 90, pp. 167-177.

[32] Liu, J.H. (2011). Fatigue life evaluation of asphalt rubber mixtures using semi-circular bending test, Advanced Materials Research, 255, pp. 3444-3449.

[33] Mohammad, L.N., Kim, M. and Elseifi M. (2012). Characterization of asphalt mixture's fracture resistance using the semi-circular bending (SCB) test, 7th RILEM International Conference on Cracking in Pavements, 4, pp. 1-10.

[34] Mirsayar, M., Shi, X. and Zollinger, D. (2017). Evaluation of interfacial bond strength between Portland cement concrete and asphalt concrete layers using bi-material SCB test specimen, Engineering Solid Mechanics, 5(4), pp. 293306.

[35] American Association of State Highway and Transportation Officials. (2013). The standard method for determining the fracture energy of asphalt mixtures using the semi circular bend geometry (SCB), AASHTO TP 105-13, Washington, DC.

[36] Ozer, H., Al-Qadi, I. L., Lambros, J., El-Khatib, A., Singhvi, P. and Doll, B. (2016). Development of the fracture-based flexibility index for asphalt concrete cracking potential using modified semi-circle bending test parameters, Construction and Building Materials, 115, pp. 390-401.

[37] Khattak, M.J., Baladi, GY. and Drzal, GY. (2007). Low-temperature binder-aggregate adhesion and mechanistic characteristics of polymer modified asphalt mixtures, J. Materials in Civil Eng, 36(2), pp. 411-22,.

[38] Champion, L., Gerard, JF., Planche, JP., Martin, D. and Anderson, D. (2001). Low-temperature fracture properties of polymer-modified asphalts relationships with the morphology, Journal of Material Science, 36(2), p. 451-60.

[39] Washington State Department of Transportation. (2016). WSDOT Highway Construction Costs, https://www.wsdot.wa.gov/Business/Construction/CostTrends.htm, Date Accessed 20/10/2018.

\section{NOMENCLATURE}

A Crack length for edge cracks or half crack length for internal cracks

$\mathrm{A}_{\text {lig }} \quad$ Ligament area

ASA Anti-Stripping Agent

BD Brazilian Disc

COV Covariance

CSTBD Cracked Straight Through Brazilian Disc

DCT Disc-shaped Compact Tension 


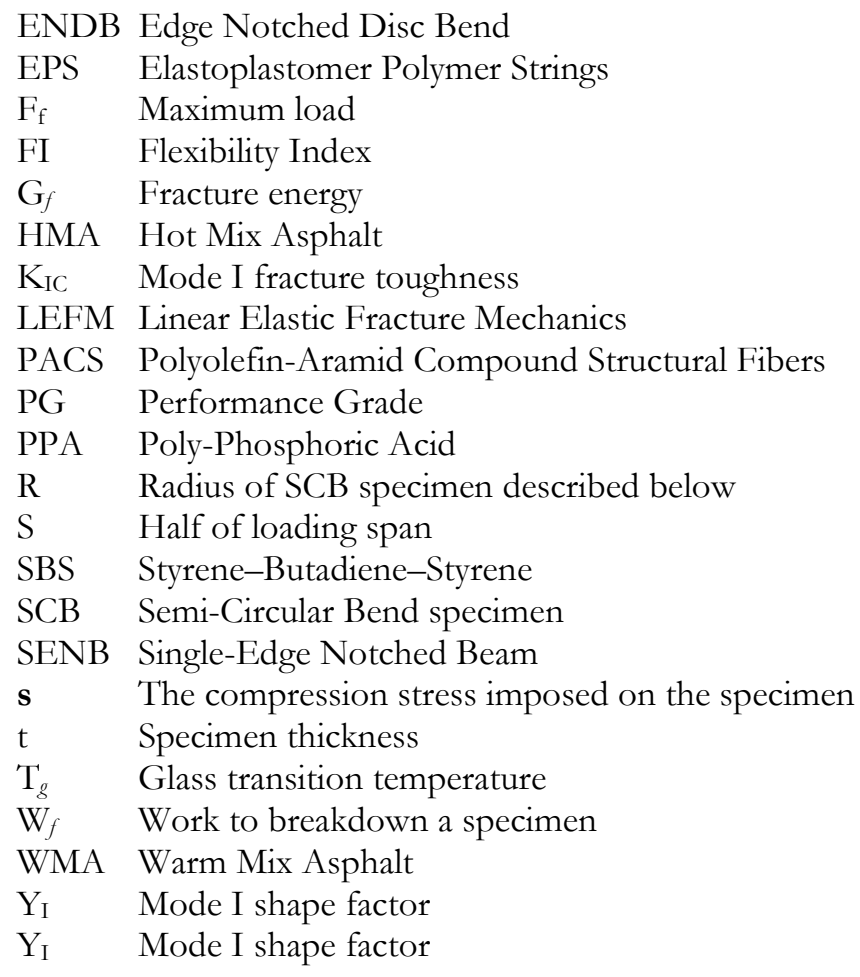

